\title{
Accidental intracerebral injection and seizure during scalp nerve blocks for awake craniotomy in a previously craniotomized patient -a case report-
}

\author{
Woo Kyung Lee ${ }^{1}$, Hyunzu Kim ${ }^{2}$, Myung-Il Bae ${ }^{1}$, Seung Ho Choi ${ }^{1}$, and \\ Kyeong Tae Min $^{1}$ \\ ${ }^{1}$ Department of Anesthesiology and Pain Medicine, Anesthesia and Pain Research Institute, Yonsei University \\ College of Medicine, Seoul, ${ }^{2}$ Department of Anesthesiology and Pain Medicine, Inha University College of Medicine, \\ Incheon, Korea
}

\begin{abstract}
A 34-year-old man who previously underwent a craniotomy due to oligodendroglioma was admitted with a diagnosis of recurrent brain tumor. An awake craniotomy was planned. Approximately 15 minutes after completing the scalp nerve block, his upper torso suddenly moved and trembled for 10 seconds, suggesting a generalized clonic seizure. He recovered gradually and fully in 55 minutes without any neurological sequelae. The emergency computed tomography scan revealed a localized fluid collection and small intracerebral hemorrhage nearby in the temporoparietal cortex beneath the skull defect. He underwent surgery under general anesthesia at 8 hours after the seizure and was discharged from the hospital after 10 days. This report documents the first case of generalized seizure that was caused by the accidental intracerebral injection of local anesthetics. Although the patient recovered completely, the clinical implications regarding the scalp infiltration technique in a patient with skull defects are discussed.
\end{abstract}

Keywords: Accidental intracerebral injection; Awake craniotomy; Previous craniotomy; Scalp nerve blocks; Seizure.

Increasing numbers of patients with skull defects are expected to get scalp infiltrations. This report presents the case of an accidental intracerebral injection of local anesthetics during

Corresponding author: Kyeong Tae Min, M.D., Ph.D.

Department of Anesthesiology and Medicine, Yonsei University College of Medicine, 50-1 Yonsei-ro, Seodaemun-gu, Seoul 03722, Korea

Tel: 82-2-2227-4161, Fax: 82-2-2227-7897

Email: ktmin501@yuhs.ac

ORCID: https://orcid.org/0000-0002-3299-4500

Received: November 20, 2017.

Revised: December 27, 2017 (1st); January 1, 2018 (2nd).

Accepted: January 3, 2018.

Korean J Anesthesiol 2018 December 71(6): 483-485 https://doi.org/10.4097/kja.d.17.00069 scalp nerve blocks in awake craniotomy in a previously craniotomized patient. The clinical pattern of seizure and recommendations for scalp infiltration in patients with skull defects are briefly discussed.

\section{Case Report}

A 34-year-old man (weight: $79 \mathrm{~kg}$, height: $180 \mathrm{~cm}$ ), who underwent removal of an oligodendroglioma in the left temporal lobe 4 years ago, was admitted for the removal of the recurrent tumor. An awake craniotomy was planned. Preoperative routine laboratory tests did not indicate any abnormal findings. The patient had no problems with cognition or communication but complained of intermittent headaches with a visual analog score of 3-5. During the preoperative assessment, he was fully

(c) This is an open-access article distributed under the terms of the Creative Commons Attribution Non-Commercial License (http://creativecommons.org/ licenses/by-nc/4.0/), which permits unrestricted non-commercial use, distribution, and reproduction in any medium, provided the original work is properly cited. 
cooperative and understood the surgical and anesthetic (asleepawake-asleep technique) procedures. Magnetic resonance imaging showed a hyperintense lesion in the left temporal pole and insula, suggesting the progression of a recurrent tumor. Computer tomography (CT) scans of the brain and skull radiography showed a bony cleft that was $2 \mathrm{~mm}$ wide in the left half of the skull (Fig. 1). Two hours prior to surgery, $1.5 \mathrm{~g}$ 5-aminolevulinic acid hydrochloride was ingested on neurosurgeon's instructions. Upon entering the operating room, pulse oximetry, non-invasive blood pressure monitoring, and electrocardiogram monitoring were applied. An arterial catheter was inserted under local anesthesia for direct blood pressure measurements. The blood pressure and pulse rate were 124/62 $\mathrm{mmHg}$ and 57 beats/min, respectively. Following the intravenous administration of $50 \mu \mathrm{g}$ fentanyl, the scalp nerve block and a ring block in the left hemisphere were performed over 30 minutes using a 25-gauge $\times 40$ $\mathrm{mm}$ needle at the supraorbital, supratrochlear, zygomaticotemporal, auriculotemporal, greater occipital, and lesser occipital nerves. A local anesthetic mixture of $60 \mathrm{ml}$ (20 $\mathrm{ml} \%$ lidocaine, $20 \mathrm{ml} 0.75 \%$ ropivacaine, and $20 \mathrm{ml}$ normal saline with 1 : 200,000 epinephrine) was used. The patient tolerated the scalp nerve block with no evidence of intravascular injection.

Approximately 15 minutes after block completion, the seizure occurred initially with a sudden move up his trunk, followed by trembling of both extremities for 10 seconds. His mentality became stupor with dilated $(7-8 \mathrm{~mm})$ pupils without light reflex. The blood pressure and heart rate were $167 / 81 \mathrm{mmHg}$ and 78 beats/min, respectively, with sinus rhythm and an oxygen saturation of $100 \%$. Although the seizure subsided spontaneously, the patient remained in a stupor with dilated and fixed pupils (right: $7 \mathrm{~mm}$; left: $8 \mathrm{~mm}$ ) with no light reflex. The operation was

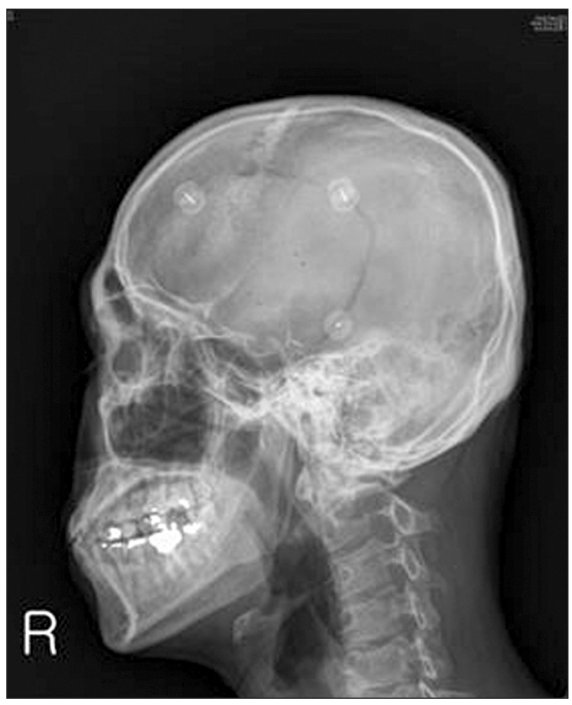

Fig. 1. Simple lateral skull X-ray shows the bony cleft due to the previous craniotomy. postponed, as it was decided that proceeding with the awake craniotomy would not be feasible, and emergency CT was conducted in order to investigate the cause of the seizures. When the scan was completed after 15 minutes, the patient remained drowsy but could respond briskly to verbal commands. His pupils were anisocoric (right: $4 \mathrm{~mm}$; left: $8 \mathrm{~mm}$ ) with light reflex. The CT scan showed a localized fluid collection and small intracerebral hemorrhage (ICH) near the temporoparietal cortex beneath the skull defect (Figs. 2 and 3). At 30 minutes after the seizure, he continued to remain drowsy but could respond to verbal commands. Pupils were asymmetric but responded well to light. At 55 minutes after the seizure, he fully recovered with-

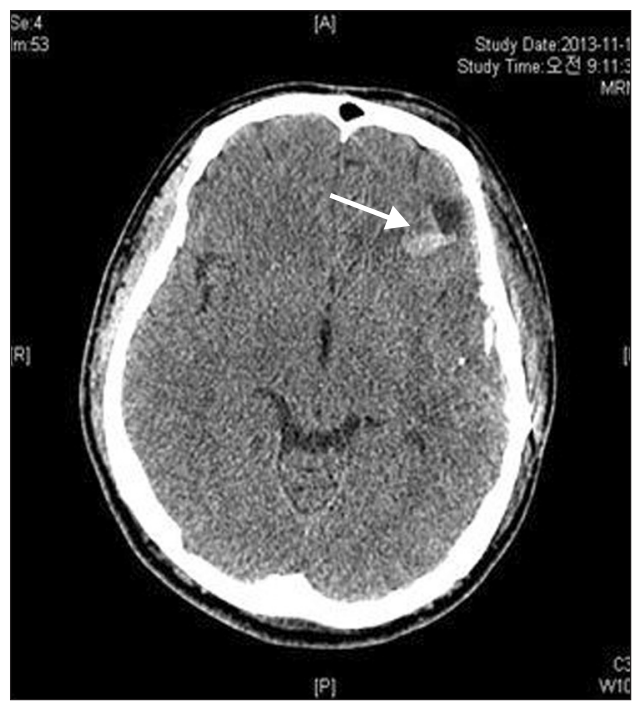

Fig. 2. Brain CT scan taken after the occurrence of seizure shows minimal intracerebral hematoma and fluid collection (arrow) in the left side.

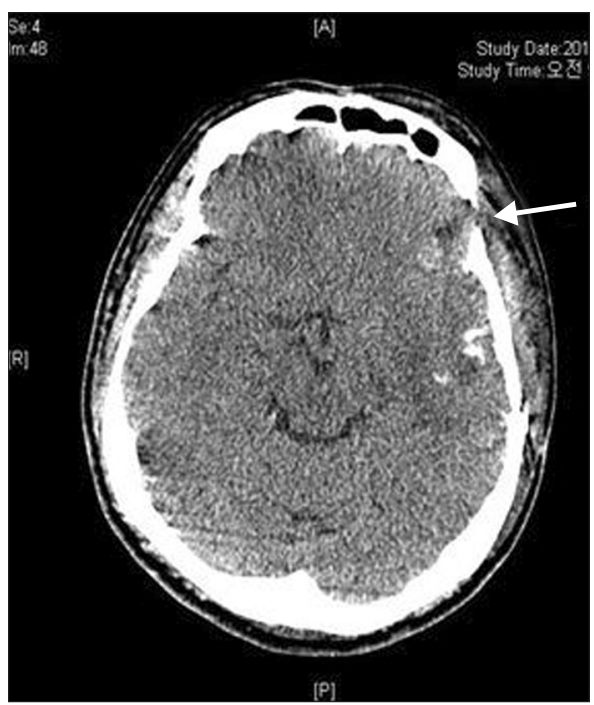

Fig. 3. Brain CT slice caudal to Fig. 2, bony cleft is visible (arrow). 
out neurological sequelae but could not recall the incident. $\mathrm{He}$ had a muscle power of 5/5 in his upper and lower extremities and a Glasgow coma scale score of 15 . His pupils were isocoric (2 $\mathrm{mm}$ ) with prompt light reflex. Prior to this, the patient had not complained of nausea, dizziness, or perioral numbness.

After being closely monitored for 1 hour and 20 minutes in the postanesthetic care unit, the patient was transferred to the neurosurgical care unit (NCU) for 6 hours and 40 minutes. Since no hemodynamic or neurological deterioration was observed, the patient was moved to an operating room, where he underwent the surgery for 7 hours and 30 minutes under general anesthesia. The lungs were extubated in the NCU 1.5 hours after the operation. He was transferred to the general ward on post-operative day 2 and released from the hospital on post-operative day 10 .

\section{Discussion}

To our knowledge, this is the first report of a seizure caused by the direct injection of local anesthetics into brain tissue. This extremely rare complication occurred after scalp nerve blocks were given during awake craniotomy in a previously craniotomized patient.

We have performed awake craniotomies using the asleepawake-asleep technique $[1,2]$. The cause of the seizure may be related to the localized accumulation of the anesthetic mixture and/or ICH, as shown in the left brain CT scan (Fig. 2). The temporal cortex was beneath the skull defect and compatible with the zygomaticotemporal nerve block site in the deep temporalis fascia. The clinical pattern of the seizure was as described above in the text. In brief, contrary to the seizure caused by systemic toxicity of local anesthetic, the generalized clonic seizure was mild and transient and was accompanied with anisocoria. The size of fluid collection in the brain parenchyma was $\sim 1.3 \mathrm{~cm}$, which corresponded to $1.15 \mathrm{ml}$, assuming the fluid accumulated spherically. Regarding mechanisms of local anesthetic-induced seizure within the brain parenchyma, vascular absorption-related systemic toxicity would be excluded, because vascular assessments were frequently conducted, and the clinical manifestation here was different from that of systemic toxicities induced by plasma concentrations of $>10 \mu \mathrm{g} / \mathrm{ml}$ lidocaine [3] or $>2.2 \mu \mathrm{g} / \mathrm{ml}$ ropivacaine [4]. The mechanism behind this clinical manifestation, including the occurrence of generalized clonic movements in both extremities despite remaining local anesthetics in the parenchyma, asymmetrical pupillary response, and amnesia, could not be established. In experimental rats, the intracerebral injection of tetrodotoxin induced a similar pupillary response [5]. Okuda et al. [6] reported a case of seizure caused by an incidental subarachnoid space injection. Unlike our case, the patient experienced general discomfort and nausea as well as loss of consciousness immediately after a lesser occipital nerve block, using $0.5 \mathrm{ml} 1 \%$ mepivacaine. The patient's saturation was maintained at over $97 \%$ despite hypoventilation. After $2 \mathrm{~h}$, the patient recovered completely without any neurological sequelae.

Increasing numbers of patients with skull defects are expected to get scalp infiltrations. To prevent complications, we recommend drawing an imaginary bony defect line from the previous craniotomy site or marking the site of the burr hole prior to performing scalp nerve blocks. The block should infiltrate as far as the imaginary line or marks. The angle of needle entry should be low around any bony defects. Scalp nerve blocks may also be performed under a C-Arm.

\section{ORCID}

Woo Kyung Lee, https://orcid.org/0000-0003-4326-6944

Hyunzu Kim, https://orcid.org/0000-0002-0625-6942

Myung-Il Bae, https://orcid.org/0000-0002-2363-4212

Seung Ho Choi, https://orcid.org/0000-0001-8442-4406

Kyeong Tae Min, https://orcid.org/0000-0002-3299-4500

\section{References}

1. Ha SH, Park IH, Lee MH, Shin SK, Min KT. Use of dexmedetomidine for awake crainiotomy. Korean J Anesthesiol 2011; 61: 346-7.

2. Osborn I, Sebeo J. "Scalp block" during craniotomy: a classic technique revisited. J Neurosurg Anesthesiol 2010; 22: 187-94.

3. Becker DE, Reed KL. Local anesthetics: review of pharmacological considerations. Anesth Prog 2012; 59: 90-101.

4. Costello TG, Cormack JR, Hoy C, Wyss A, Braniff V, Martin K, et al. Plasma ropivacaine levels following scalp block for awake craniotomy. J Neurosurg Anesthesiol 2004; 16: 147-50.

5. Zhuravin IA, Bures J. Extent of the tetrodotoxin induced blockade examined by pupillary paralysis elicited by intracerebral injection of the drug. Exp Brain Res 1991; 83: 687-90.

6. Okuda Y, Matsumoto T, Shinohara M, Kitajima T, Kim P. Sudden unconsciousness during a lesser occipital nerve block in a patient with the occipital bone defect. Eur J Anaesthesiol 2001; 18: 829-32. 